Revista Universo Contábil, ISSN 1809-3337

FURB, v. 5, n. 2, p. 71-86, abr./jun., 2009

doi:10.4270/ruc. 2009214

Disponível em www.furb.br/universocontabil

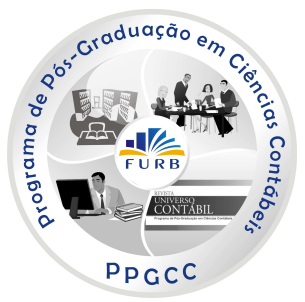

\title{
ANÁLISE DO IMPACTO DA VARIAÇÃO CAMBIAL NO PREÇO DE TRANSFERÊNCIA E NO RESULTADO DO PERÍODO: O CASO DA FIAT AUTOMÓVEIS S/A*
}

\section{THE IMPACT OF EXCHANGE RATE VARIATION IN THE TRANSFER PRICE AND EARNINGS: FIAT S/A CASE}

\author{
Igor dos Santos Fischer \\ Bacharel em Ciências Contábeis pela UFMG \\ Endereço: Rua Antônio Carlos, 6.627 - Bairro Pampulha \\ CEP: 31270-901 - Belo Horizonte/MG - Brasil \\ E-mail: igor.fischer@fiat.com.br \\ Telefone: (31) 3409-7265 \\ Romualdo Douglas Colauto \\ Doutor em Engenharia de Produção pela EPS/UFSC \\ Professor da Universidade federal de Minas Gerais \\ Endereço: Rua Antônio Carlos, 6.627 - Pampulha \\ CEP: 31270-901 - Belo Horizonte/MG - Brasil \\ E-mail: rdcolauto@face.ufmg.br \\ Telefone: (31) 3409-7265
}

\section{RESUMO}

As companhias que transferem produtos entre unidades do mesmo grupo empresarial utilizam-se do Preço de Transferência para operacionalizar tais transações. Quando uma unidade do grupo empresarial está situada no exterior, os preços são, na maioria das vezes, acordados em moedas estrangeiras e, por isso, estão vulneráveis às oscilações das taxas cambiais. No ano de 2005, a moeda nacional brasileira apresentou valorização significativa comparada ao Dólar e ao Euro. Conseqüentemente, as receitas de exportação de companhias com subsidiárias no mercado externo que utilizam Preço de Transferência foram impactadas pelo comportamento do câmbio do Brasil. Assim, o objetivo do trabalho é mostrar o impacto da valorização do Real no resultado contábil do período comparado ao Dólar e ao Euro em

\footnotetext{
Artigo recebido em 12.10.2007. Revisado por pares em 10.09.2008. Reformulado em 06.11.2008. Recomendado em 20.11.2008 por Ilse Maria Beuren (Editora). Publicado em 30.06.2009. Organização responsável pelo periódico: FURB.
} 
uma empresa automobilística que utiliza o Preço de Transferência para mensuração das receitas de exportação. Para tanto, realizou-se um estudo exploratório com abordagem lógica dedutiva, por meio de um estudo de caso centrado na Fiat Automóveis S/A. Os dados empíricos referentes à empresa pesquisada foram extraídos das demonstrações contábeis publicadas, dos registros existentes na organização e de entrevistas não estruturadas no setor de controladoria da subsidiária brasileira. Os resultados mostram que a valorização da moeda brasileira não foi favorável para o resultado contábil da empresa, reduzindo a receita bruta de vendas e, conseqüentemente o lucro.

Palavras-chave: Preço de Transferência. Taxa de câmbio. Variação cambial.

\section{ABSTRACT}

A company that transfers products among units of the same business group uses Transfer Price to make these operations. When a unit of the business group is located in a foreign country, the prices usually are agreed upon foreign currency and, thus, are vulnerable to oscillations in the exchange rate. In 2005, the Brazilian national currency had a significant appraisal compared to Dollar and Euro. As a consequence, the exportation revenues of companies with branches in foreign countries that use Transfer Price were affected by the behavior of the Brazilians exchange rate. Thus, this research objective is to show the impact of the appraisal of Real in the accounting result comparing to Dollar and Euro on an automotive industry that uses Transfer Price to measure its exportations' revenues. Therefore, an exploratory study with logical deductive approach was performed through a case study focused on FIAT Automóveis S/A. The company's empirical analyzed data were extracted from published accounting statements, from the enterprise's records and from non structured interviews with the Brazilian branch's controlling sector. The result shows that the appraisal of Brazilian's currency wasn't favorable to the company's accounting results, reducing its sales gross revenues and, consequently, its profits.

Keywords: Transfer Price. Exchange Rate. Exchange Rate Variation.

\section{INTRODUÇÃO}

As dificuldades de ordem econômico-financeiras decorrentes de uma conjuntura complexa contribuem para tornar o custo um tema relevante na gestão das organizações privadas e públicas, sejam elas de fins lucrativos ou não. Em função das pressões ambientais, as empresas buscam os melhores instrumentos gerenciais para servir como suporte à tomada de decisões. Consideram que ao longo do tempo, os concorrentes conseguem igualar-se à qualidade e ao preço do atual produto líder de mercado. Em resposta, emerge a importância de decisões adequadas para assegurar a eficiência e a eficácia empresariais.

A filosofia organizacional atual é a descentralização. Um dos principais desafios na operação de um sistema descentralizado está em se criar metodologias satisfatórias para contabilizar bens e serviços transferidos de uma unidade de negócio para outra. Uma das alternativas mais expressivas para solucionar a questão é utilizar adequadamente Preços de Transferência (PT) (ANTHONY; GOVINDARAJAN, 2000).

A metodologia do PT pode ser utilizada quando se deseja mensurar o resultado de unidades de negócios ou interdepartamentais em função de transferência de produtos. Assim pode ser utilizada na venda de produtos entre grupos empresariais, inclusive aqueles sediados em outros países. Nesse caso específico, os preços praticados nas transações geralmente são acordados em moedas estrangeiras e, com isso sofrem influência das taxas cambias. 
No contexto brasileiro, após a implantação do Plano Real a moeda nacional adquiriu certa estabilidade. Todavia, não ficou incólume às desvalorizações, principalmente àquelas compreendidas entre 1997 e 2002, quando ocorreram as crises asiática, russa, brasileira e argentina. Deve-se ressalta que em específico, no ano de 2005, o Plano Real apresentou um comportamento atípico. Devido a fatores macroeconômicos o Real valorizou frente às demais moedas estrangeiras, sobretudo em relação ao Dólar e ao Euro. O fenômeno provocou impactos nas atividades das empresas e influenciou as exportações. Assim, as empresas diminuíram a quantidade de vendas para o mercado externo, perderam receita, deixaram de contratar e, em alguns casos, reduziram o quadro funcional em razão da queda do volume de negociações. Outra influência da oscilação da taxa de câmbio são as perdas ocasionadas em função de operações em que os preços de venda estão fixados em moeda estrangeira. Nessas transações ocorre uma redução da receita operacional, influenciando, conseqüentemente, $o$ resultado líquido do período.

Nas operações entre empresas do mesmo grupo, existem critérios para se definir o preço praticado entre elas. Em relação à empresa Fiat Automóveis S/A, a matriz situa-se no exterior e a definição do PT é realizada em Dólar ou Euro. Quando ocorrem vendas para a matriz ou alguma empresa vinculada do mesmo grupo, o valor da operação em moeda estrangeira é convertido pela taxa do câmbio do dia. Os produtos da companhia possuem uma parte dos custos representada por insumos nacionais e por decorrência vendidos em moeda nacional brasileira. Portanto, os custos desses componentes somente variam em função da inflação do Brasil e não sofrem influência da variação do câmbio interno, haja vista que os componentes são de origem interna. Com a valorização do Real há redução do resultado operacional, uma vez que o preço de venda fixado em moeda estrangeira diminui. O custo, porém, não é influenciado por essa variação e permanece o mesmo. Isso resulta na redução da margem de contribuição e, conseqüentemente, no lucro final do período.

Dependendo do impacto sofrido, a empresa precisa tomar decisões importantes e rápidas para minimizar as distorções ocasionadas pela variação cambial. Para isso, necessitase mensurar e monitorar o impacto no resultado para auxiliar as decisões de curto e longo prazo. Assim, o objetivo do trabalho é mostrar o impacto da valorização do Real no resultado do período comparado ao Dólar e ao Euro em uma empresa automobilística que utiliza PT para mensuração das receitas de exportação.

No campo teórico, a pesquisa justifica-se pelo fato da variação cambial influenciar na avaliação do resultado do período em que se observa a valorização ou desvalorização da moeda nacional em comparação à estrangeira. $\mathrm{O}$ registro contábil a valor histórico se torna distorcido, uma vez que os valores representam níveis econômicos diferentes. Essa situação é semelhante àquela de economias com alto grau de inflação em que a moeda perde o poder aquisitivo. E em função dessa perda de representatividade da moeda, os contadores e autoridades fiscais têm-se preocupado em desenvolver e aprimorar técnicas que permitam mensurar com maior precisão a posição financeira da empresa e seu resultado operacional.

$\mathrm{Na}$ área prática, a pesquisa denotará o impacto sofrido pela variação da taxa de câmbio em operações externas que envolvem o PT para auxiliar tomada de decisões estratégica. E na área social, a pesquisa fornecerá informações a respeito dos efeitos das oscilações cambiais nas informações econômicas e financeiras apresentadas nas demonstrações contábeis. Assim, como a empresa estudada, outras várias também sofreram os mesmos impactos. Numa visão geral, permitirá perceber a influência na balança comercial num momento em que o país incentiva as exportações.

A limitação da pesquisa reside na validação externa dos resultados obtidos uma vez que, por se tratar de um estudo de caso, não é possível generalizá-los. Para que isso fosse possível seria necessário um estudo empírico abrangente envolvendo um maior número de observações. 


\section{PROCEDIMENTOS METODOLÓGICOS}

O delineamento da pesquisa configura-se como estudo exploratório que se utiliza de fontes primárias e secundárias, com abordagem lógica dedutiva. De acordo com Gil (1995) as pesquisas exploratórias têm como principal finalidade desenvolver, esclarecer e modificar conceitos e idéias, com vistas na formulação de problemas mais precisos ou hipóteses pesquisáveis para estudos posteriores. As fontes secundárias serão compostas por pesquisa bibliográfica para a formação do marco referencial teórico e de um estudo de caso centrado em uma única organização. Segundo Yin (1984), um estudo de caso é uma investigação empírica que investiga um fenômeno contemporâneo dentro de seu contexto da vida real, quando os limites entre fenômeno e contexto não estão claramente delimitados e várias fontes de evidências são utilizadas.

A escolha do sujeito da pesquisa foi intencional e principalmente pela acessibilidade às informações necessárias. Os dados referentes à empresa pesquisada foram extraídos das demonstrações contábeis publicadas, dos registros existentes na organização e de entrevistas não estruturadas com a controladoria da companhia. Segundo Richardson (1999), a entrevista não estruturada procura saber o quê, como e o porquê de algo ocorrer, em lugar de determinar a freqüência de certas ocorrências.

Quanto aos procedimentos sistemáticos para a descrição e explicação dos fenômenos, o estudo se desenvolverá num ambiente que preconiza a abordagem qualitativa. A abordagem qualitativa é empregada para a compreensão de fenômenos caracterizados por um grau elevado de complexidade e, por isso, nela são concebidas análises mais aprofundadas sobre o fenômeno estudado. De acordo com Richardson (1999), o método qualitativo tem como característica a não utilização de instrumentos estatísticos como base para a análise de um problema, ou seja, não se prende a numerar ou medir unidades ou categorias homogêneas.

\section{ABORDAGEM CONCEITUAL DO PREÇO DE TRANSFERÊNCIA}

De acordo com Atkinson et al. (2000), o PT é um conjunto de regras que a empresa usa para distribuir as receitas e os custos entre os centros de responsabilidade. Estas regras podem ser arbitradas quando há um alto nível de interação entre os centros de responsabilidade e eles determinam os valores de transferências internas, os quais distribuirão as receitas arrecadadas na empresa para os centros de lucros individuais, afetando o lucro informado de cada centro. Para Pereira e Oliveira (2001), além da mensuração das contribuições das atividades para o resultado da empresa, o preço de transferência também incorpora características que estimulam os gestores a buscar o sucesso da empresa como um todo. Quando mais de um centro de lucro é responsável pelo desenvolvimento de um produto, ambos devem compartilhar a receita deste, quando de sua venda (ANTHONY; GOVINDARAJAN, 2002). O PT representa um mecanismo de distribuição dessa receita, sendo um instrumento de atuação que motiva os executivos a tomarem as decisões corretas (WACHHOLZ; BENETTI; REGINATO, 2005).

As empresas podem possuir operações centralizadas e descentralizadas. Na primeira modalidade, as decisões de planejamento e operações são tomadas pela alta administração. $\mathrm{Na}$ segunda, a empresa é organizada em divisões ou unidades operacionais, administradas por gerentes que possuem responsabilidades de planejar e controlar as operações de suas unidades. Em pequenas empresas operadas pelos sócios proprietários a centralização pode ser desejada, pois garante o andamento das atividades da forma por eles almejada. Entretanto, em grandes organizações, o controle das atividades de forma centralizada na figura do proprietário se torna inviável, sendo necessária a operação descentralizada (WARREN; REEVE; FESS, 2001). 
Nas empresas que operam de forma descentralizada, os produtos de uma divisão podem ser utilizados como matéria-prima entre outras. Warren, Reeve e Fess (2001 p. 282) afirmam que "quando as divisões transferem produtos ou serviços entre si, é usado um PT para debitar a transferência". Segundo Hansen e Mowen (2003), são os valores cobrados pelos artigos produzidos por uma divisão e transferidos para outra. Castelli (1999, apud Medeiros, 2000 p.49) define PT como "o valor pelo qual são transferidos bens e serviços entre as atividades e áreas internas de uma organização". Para Garrison e Norren (2001 p.403), é "o preço cobrado quando um segmento da companhia fornece bens ou serviços a outro segmento". Hilton (1997 p.644) explica ser "a quantia cobrada quando uma divisão vende bens ou serviços para outra“".

O PT refere-se ao valor estipulado a um artigo produzido por uma unidade divisional da empresa e transferido para outra unidade que o utilizará como parte dos insumos. É empregado para ajudar a coordenar as decisões e alcançar os objetivos da corporação como um todo, além de dar condições às divisões de tomarem decisões com relação ao preço final do produto. Esse preço representa uma receita para a divisão produtora e uma despesa para a divisão compradora (MEDEIROS, 2000).

Como os PT afetam tanto as divisões produtoras como as compradoras, a definição desses preços constitui uma questão prioritária para os gestores de divisões. Assim, devem ser definidos de modo a maximizar o lucro da empresa quando os produtos forem transferidos de uma unidade operativa para outra. Entretanto, quando usados inadequadamente, podem prejudicar o lucro das organizações. De acordo com Hansen e Mowen (2003), na maior parte das empresas a alta gestão raramente define os preços específicos de transferência entre as divisões. Às vezes as organizações desenvolvem políticas gerais para as unidades operativas seguirem. Os gerentes divisionais têm interesse na forma como o PT é estabelecido, pois estes podem ter efeitos significativos sobre a lucratividade das divisões.

Hilton (1997), Garrison e Norren (2001), Warren, Reeve e Fess (2001) e Hansen e Mowen (2003) expõem que as políticas mais comumente utilizadas pelas organizações são: a) Preço de Transferência com base no custo; b) Preço de Transferência com base no mercado; e, c) Preço de Transferência com base no preço negociado. Entretanto, para Atkinson et al. (2000), além dessas três políticas existe a do Preço de Transferência Administrado.

Mauro (1991, apud MEDEIROS, 2000 p. 42) explica que no conceito de preço de transferência, a polêmica entre os estudiosos "não se encontra centrada na ênfase de estruturação de modelos, que todos, em princípio, acordam ser fundamentalmente a mesma, e sim, nas vantagens para o processo gerencial da organização decorrente da adoção de um ou outro dos modelos". Portanto, além de definir a política de formação do PT as empresas devem analisar se essa política adotada é a melhor.

\subsection{Preço de transferência com base no mercado}

O Preço de Transferência com base no mercado é aquele ao qual o produto ou serviço poderia ser vendido a compradores externos (WARREN; REEVE; FESS, 2001). Para essa política ser aplicada faz-se necessário existir um mercado intermediário para o produto a ser transferido. Conforme Garrison e Norren (2001, p. 407), mercado intermediário é "um mercado em que o produto ou serviço é vendido na sua forma atual para clientes externos". Caso exista um mercado no qual o produto a ser transferido possa ser vendido a outros clientes, o preço pela qual a mercadoria será vendida representa o PT que deverá ser aplicado.

Para essa política ser aplicada, é necessário que o mercado intermediário seja perfeitamente competitivo, onde os produtores não influenciam no preço dos produtos. E, caso exista o preço com base no mercado, este será o mais indicado. Segundo Hansen e Mowen (2003, p. 335), se existir esse cenário, as "ações dos gestores irão simultaneamente, otimizar os lucros divisionais e os lucros de toda a empresa. Além disso, nenhuma divisão se 
beneficiará à custa de outra divisão. Nesse cenário, a gestão central não será tentada a intervir".

Na abordagem do preço de mercado, a divisão vendedora deve ter a opção de produzir bens para a transferência interna ou para vendas no mercado intermediário. Da mesma forma, a divisão compradora precisa possuir autonomia para adquirir os produtos de um fornecedor externo ou da própria organização. Porém, há momentos em que a utilização do preço de mercado não é apropriada. Ocasionalmente o mercado passará por momentos em que haverá uma oferta muito grande e preços baixos. A estipulação de um PT baseado no mercado sobre essas condições pode levar a decisões que não são as melhores para o interesse da empresa. Os gerentes divisionais podem agir de forma a priorizar o lucro da unidade operativa, mesmo que contrarie interesses da empresa como um todo. Uma solução para tal situação é estabelecer preços iguais à média do preço praticado pelo mercado por um longo período (HILTON, 1997).

\subsection{Preço de transferência com base no preço negociado}

A existência de mercados intermediários perfeitamente concorrenciais é rara e, na maioria dos casos os produtores podem interferir no preço dos produtos. Quando essas imperfeições de mercado existem, a abordagem do preço de mercado não é a mais adequada. Nessas situações o Preço de Transferência com base no preço negociado mostra-se uma alternativa prática (HANSEN; MOWEN, 2003). De acordo com Garrison e Noreen (2001), o PT negociado representa o preço acertado entre a divisão que compra e a divisão que vende. Para Hilton (1997), a política do preço negociado é aquela em que os gerentes divisionais podem negociar o preço pretendido.

A política do preço negociado permite aos gerentes das unidades operativas chegarem a um acordo (negociar) sobre o preço que será praticado entre eles. O principal ponto a ser observado nessa negociação reside no valor do PT ser, necessariamente, menor que o preço de mercado para estimular a divisão compradora a adquirir o produto internamente. Todavia, deverá ser maior que os custos variáveis da divisão fornecedora para não prejudicá-la (WARREN; REEVE; FESS, 2001). Algumas vezes, conforme expõe Hilton (1997), a negociação inicia-se a partir do preço de mercado e em seguida são realizados ajustes por vários motivos.

Garrison e Norren (2001) mostram que o PT com base no preço negociado possui algumas vantagens: a) preserva a autonomia das divisões; e b) os gerentes divisionais normalmente possuem melhores informações a respeito dos custos e benefícios potenciais do que os demais gerentes da empresa. Além disso, se aplica perfeitamente em casos de capacidade ociosa e custos necessários para a distribuição do produto que podem ser evitados em função da transferência interna.

Em situações em que há capacidade ociosa, a unidade fornecedora não consegue vender tudo o que é capaz de produzir. Dessa maneira, a transferência interna é uma forma de aumentar as vendas. E, uma vez que os custos fixos já estão pagos pela produção normal e não há perda de vendas externas, o preço estabelecido pode ser menor que o de mercado, porém deve ser maior que o custo variável de produção. Com isso o lucro da empresa melhora em função do aumento da produção e receita da unidade fornecedora e da redução do custo da unidade compradora (MOWEN; HANSEN, 2003).

No outro caso, custos de distribuição evitáveis, a unidade fornecedora possui custos de distribuição que podem ser evitados caso a venda seja efetuada para outra divisão da empresa, como comissão de vendas, por exemplo. Com isso, um produto pode ser transferido para outra unidade operativa da empresa por um preço menor que o praticado no mercado, porém deve ser menor que o preço de mercado subtraído dos custos de distribuição evitáveis. Desse 
modo, os ganhos da empresa aumentariam por reduzir os custos nas duas divisões (MOWEN; HANSEN, 2003).

Hilton (1997) expõe que o PT com base no preço negociado possui desvantagens, dentre elas, a de a metodologia levar a desentendimentos e competições entre gerentes divisionais. Para Atkinson et al. (2000), os gestores podem negociar visando à melhoria dos resultados se suas divisões e os preços acordados podem não serem os que beneficiam a empresa como um todo. Garrison e Norren (2001) afirmam que nem todos os gerentes compreendem o negócio ou são cooperativos, interferindo negativamente na negociação. De acordo com Hansen e Mowen (2003), os gestores divisionais podem possuir informações confidenciais e querer tirar vantagem de outro gestor como, por exemplo, mentir sobre seus custos de produção. Outra desvantagem é que a negociação pode consumir tempo e recursos consideráveis. Mesmo assim, se a negociação for conduzida com coerência e integridade, pode aumentar a lucratividade de cada divisão e da empresa como um todo.

\subsection{Preço de transferência com base no custo}

O Preço de Transferência embasado no custo de produção emprega custos reais ou padrões (orçados) para seus cálculos. Hilton (1997) menciona que ao utilizar custos reais as ineficiências de uma divisão são transferidas para outra, uma vez que o consumo de recursos acima do padrão ou a compra deles por preços mais expressivos aumenta o custo do produto a ser transferido. Para evitar essa desmotivação no controle dos custos é preferível utilizar o custo padrão para a formação do preço de transferência. Com isso, a unidade fornecedora terá um preço bem definido a ser utilizado nas transferências. Caso resista a monitorar seus custos, ela poderá acumular prejuízos nessas operações.

Nesse aspecto é possível utilizar custos totais ou somente os custos variáveis para definir o preço de transferência. Ao utilizar os custos totais, são incluídos no cálculo os custos de materiais diretos, a mão-de-obra direta e os custos indiretos de fabricação. Optando-se pelos custos variáveis, os custos indiretos de fabricação são excluídos do PT e são considerados somente os materiais diretos e a mão-de-obra direta (WARREN; REEVE; FESS, 2001).

Para Atkinson et al. (2000), um fator a ser analisado quando se compõe o PT a partir do custo é o mark up. Deve-se definir se será usado somente o custo de fabricação ou acrescentará a ele uma margem. No primeiro caso a divisão fornecedora não obterá lucro nenhum na fabricação do produto, ele ficará inteiramente com a divisão seguinte quando realizar a venda do produto final. No segundo haverá definição de uma margem para a divisão fornecedora e isso faz com que o lucro obtido pela empresa seja mais bem distribuído entre as suas divisões. Conforme Hilton (1997), em casos de transferências entre divisões que estão em países diferentes a fixação dessa margem se torna fundamental para definir em qual país o lucro da empresa será tributado.

Apesar de a principal vantagem ser a simplicidade de aplicação e de possuir várias desvantagens, o PT com base no custo é muito utilizado pelas organizações. Existem algumas justificativas para tal fato. Em algumas empresas o impacto causado na lucratividade pelas transferências internas é pequeno e seria mais benéfico utilizar o custo para elaborar o Preço de Transferência a gastar tempo e recursos em negociações. Da mesma forma, quando se transfere produtos solicitados sob encomenda e cujos valores são difíceis de identificar no mercado é mais vantajoso utilizar tal metodologia (HANSEN; MOWEN, 2003).

\subsection{Preço de transferência administrado}

Na prática do Preço de Transferência Administrado, o gestor arbitra uma política para transferências internas. Essa política é baseada nas três anteriores, como por exemplo, $80 \%$ do 
preço de mercado ou custo fixo mais 5\%. As empresas, freqüentemente, usam o preço administrado quando uma transação particular acontece sempre. Porém, essa política não reflete as considerações econômicas, como fazem os preços baseados no mercado e no custo, nem as considerações de responsabilidade, como fazem os preços negociados.

Esse método é de fácil aplicação e evita conflito entre as duas partes da relação do Preço de Transferência. Entretanto, essa regra utiliza uma distribuição arbitrária de receitas e custos entre as divisões da empresa. Além disso, gera subsídios entre as divisões que dificultam a interpretação econômica normal de suas receitas e seus custos. Isso pode gerar um efeito motivacional negativo se os membros de alguma unidade operativa acreditarem que a aplicação da regra é injusta (WACHHOLZ; BENETTI; REGINATO, 2005). Dessa forma, o preço administrado denota ser de mais fácil aplicação por se tratar de uma regra arbitrada, porém, viola o espírito da abordagem de responsabilidade trazida pela descentralização.

\section{EFEITOS DA VARIAÇÃo CAMBIAL NO PREÇO DE tRANSFERÊNCIA E RESULTADO DO EXERCÍCIO}

De acordo com Moffitt (1984), após Reunião de Bretton Woods e a substituição do ouro pelo Dólar como centro do sistema monetário internacional, a taxa de câmbio Cruzeiro versus Dólar era fixa e só poderia ser reajustada em função de desequilíbrio dos balanços de pagamentos. Nesse período, a alta inflação do Brasil foi o principal motivo das variações cambiais. E como a inflação brasileira era muito maior do que a externa, essas variações desvalorizavam a moeda brasileira.

Após cinco décadas e seis trocas de moeda, o Brasil ainda tinha como principal fator de variação da taxa de câmbio a sua inflação. Nos sistemas de taxas múltiplas, fixas em degraus e minidesvalorizações, a inflação brasileira ainda distorcia o nível econômico do país em relação ao resto do mundo. Quando o Plano Real foi implantado, juntamente com o sistema de taxas de câmbio flutuantes, a inflação foi controlada e manteve-se em um patamar razoável. Com isso, essa variável já não era mais o motivo de variações cambiais. Garofalo Filho (2000, p.150) afirma que o novo regime cambial "deve pressupor uma direção errática da taxa, ora se valorizando, ora se desvalorizando". Essa flutuação ocorre porque as taxas flutuantes são baseadas na lei de mercado. Quando a demanda por moeda estrangeira é abundante a taxa se desvaloriza, quando a oferta é grande, se valoriza. Conforme Simonsen (1995, p. 159) nesse tipo de regime "a oferta de moeda estrangeira provém dos exportadores, [...], e dos que trazem capitais e seus rendimentos para o país [...]. A procura resulta das importações, das remessas de rendimentos e da repatriação de capitais [...]. Assim, o jogo das forças do mercado leva ao equilíbrio da taxa de câmbio".

Para Garofalo Filho (2000), a oferta de moedas internacionais resulta das exportações de bens e serviços, do turismo receptivo, da captação de recursos externos, como empréstimos e financiamentos, do ouro extraído no país e dos recebimentos diversos, como dividendos e royalties. A demanda provém das importações de bens e serviços, do turismo remissivo, de pagamentos diversos, como lucros e dividendos, das amortizações e pagamentos de empréstimos e financiamentos, investimentos no exterior de residentes no Brasil e do entesouramento.

A taxa de câmbio representa a equivalência monetária entre a moeda nacional e as estrangeiras. A cotação pode alterar diariamente em função da inflação interna ou externa, políticas governamentais de incentivo às importações ou exportações, e por outros motivos (ALMEIDA, 1997). A modificação da paridade cambial gera variações de preços convertidos em Real de produtos exportados em moedas internacionais. Quando os preços se alteram no mercado refletem em aumentos ou diminuições do valor da unidade monetária e, consequentemente, do poder aquisitivo. O poder aquisitivo refere-se à capacidade de comprar bens e serviços com uma dada quantidade de moeda em comparação com o que a mesma 
quantia teria permitido adquirir em data anterior. As variações ocorrem somente quando os preços de bens ou serviços são distintos dos que eram anteriormente e, por isso, resultam numa alteração de receita (HENDRIKSEN, 1999).

A desvalorização cambial descomprime a pressão concorrencial exercida no mercado internacional e tende a ampliar a capacidade das firmas de elevarem as margens. Por outro lado, uma valorização diminui a competitividade do produto no exterior e geralmente reduz as margens. Outra conexão é o custo industrial. O impacto é proporcional à quantidade de material importado utilizado na composição da estrutura de custos (PEREIRA; CARVALHO, 2000).

Um produto negociado no exterior tem seu preço definido em moeda internacional. Ao modificar a paridade cambial o poder de compra da moeda também se altera. Quando a taxa de conversão desvaloriza, a capacidade de aquisição da moeda nacional diminui no mercado externo, o que se traduz em uma necessidade maior de Reais para equivaler-se a um Dólar ou Euro. De acordo com Rezende (1999), a desvalorização torna o país mais competitivo e as exportações ficam relativamente mais baratas e tendem a aumentar. O fenômeno faz com que a receita e a margem do produto exportado cresçam. Entretanto, se o bem utiliza insumos importados o impacto pode ser diferente. Como é necessário um volume maior de moeda nacional para converter-se em moeda estrangeiras, o preço da mercadoria proveniente do exterior aumenta, elevando o custo do bem. Isso reduz a receita das vendas externas e comprime o mark up da empresa. Mas, no caso de importação de insumos, os preços internacionais ficam mais baratos ao serem convertidos, reduzindo o custo dos produtos que possuem itens provenientes de outros países em sua composição.

Não considerando possibilidades de alterações na quantidade de produtos vendidos, a variação cambial pode aumentar ou reduzir a receita e os custos e, consequientemente afeta o resultado da empresa. Na desvalorização há um aumento da receita bruta de vendas e do custo dos produtos vendidos. Na valorização há redução desses dois fatores. Como são de naturezas distintas, o impacto no lucro ou prejuízo dependerá do volume de exportação e da proporção de material importado nos custos dos produtos. Na primeira situação, desvalorização da taxa de câmbio, se os valores das transações no mercado externo forem maiores que a participação de insumos importados no custo haverá melhoria do resultado, sendo o inverso também verdadeiro. Em outra vertente, na apreciação da paridade cambial, se a redução das exportações superar a dos custos, o resultado será reduzido já o oposto tende a melhorar.

O PT para a unidade fornecedora é receita e aumenta seu resultado. É evidente que a divisão deseja que esse preço seja o mais alto possível. Para a unidade compradora, o mesmo PT representa custo e diminui seus resultados. Parece ser lógico que essa divisão procurará fazer esse preço o menor possível. Entretanto, para a empresa como um todo, não há impacto no resultado, uma vez que a receita da divisão vendedora menos o custo da divisão compradora será zero (HANSEN; MOWEN, 2003).

Mesmo prevendo esse impacto no resultado da empresa, o PT tem a capacidade de influenciar no resultado divisional. Seu valor pode fazer com que o lucro fique distribuído desigualmente entre as divisões, deixando uma unidade de negócio com um lucro maior que a outra e, em casos extremos, deixar uma divisão com prejuízo e a outra com lucro. Essa análise se torna ainda mais relevante quando as divisões estão localizadas em países diferentes. Se a divisão fornecedora encontra-se instalada no Brasil, por exemplo, e a divisão compradora no exterior, e a tributação do governo brasileiro for maior que a dos outros governos, ao transferir um produto para países estrangeiros, a empresa o fará por um valor baixo e, se possível, inferior ao custo de produção. Com isso a unidade de negócios brasileira terá lucros inferiores, ou até mesmo prejuízo, enquanto as unidades do exterior desfrutarão de uma proporção maior lucro na transação. 
Nesse contexto, o resultado global da empresa não se altera diretamente. Certamente o lucro final será o mesmo, mas a tributação sofrida será menor, caso a maior parte dos lucros permaneça no Brasil. Com isso o resultado da empresa melhora em função da redução da carga tributária. A mesma situação pode ser encontrada quando a divisão fornecedora localizar-se em um país estrangeiro e a divisão compradora estiver no Brasil. Porém, nesse caso, o PT tenderá a ser o máximo possível para que se aumente a receita da divisão estrangeira e transfira-se o lucro para o exterior (GARRISON; NOREEN, 2001).

Conforme Hansen e Mowen (2003), mesmo tendo impacto zero no resultado da empresa como um todo, em certas ocasiões o PT gera situações que influenciam no resultado. Se a divisão fornecedora estabelecer, por exemplo, um PT maior que o preço praticado no mercado, a divisão compradora irá adquirir o produto externamente. Em situações da divisão vendedora não substituir as vendas internas pelas externas incorrer-se-á em prejuízo. Deve-se considerar que a divisão compradora diminuirá seus custos, porém a outra divisão não venderá seus produtos. Conseqüentemente, a atuação independente das unidades produtivas e a forma como os PT são estabelecidos são críticos na apuração do resultado global.

\section{DESCRIÇÃO E ANÁLISE DOS DADOS}

\subsection{Caracterização da empresa objeto de estudo}

A Fiat Automóveis S/A é uma empresa controlada do Grupo Fiat SpA. O Grupo Fiat é um dos maiores grupos industriais da Itália e do mundo, com operação em mais de 60 países. Na divisão de automóveis, a Fiat Auto SpA, possui atividades no Brasil e em outros países, mas o mercado brasileiro é o principal do grupo depois do Italiano, além de sediar a mais importante fábrica de automóveis fora da Itália. Com isso, a empresa ocupa atualmente um lugar de destaque na estratégia global do grupo.

A Fiat Automóveis S/A está instalada em Betim/MG, região metropolitana de Belo Horizonte. Possui $2.250 .000 \mathrm{~m}^{2}$ de área total e capacidade de produção de 2.440 carros por dia. Atualmente opera em dois turnos fabricando aproximadamente 2.200 carros diariamente. A companhia possui cerca de 18.500 trabalhadores, sendo 9.000 funcionários próprios da empresa e 9.500 terceirizados. Além disso, possui 260 empresas fornecedoras de autopeças. No ano de 2005 obteve um faturamento na ordem de 13,1 bilhões de reais. Esse valor foi $25 \%$ superior ao do ano anterior. No mercado interno, emplacou 404.803 veículos e reassumiu a liderança de vendas. As exportações totalizaram aproximadamente 100.000 unidades, representando um aumento de 30,5\% em comparação ao ano de 2004. Os indicadores refletem a importância do mercado externo para a empresa, uma vez que representa cerca de $20 \%$ do faturamento.

\subsection{Precificação e políticas de formação do preço de transferência na empresa}

A Fiat Automóveis S/A tem dedicado, nos últimos anos, uma atenção especial às exportações. A companhia comercializa produtos para vários países e, além do Brasil e da matriz na Itália, possui fábricas na Argentina, África do Sul, Polônia, Turquia, China e outros. A divisão brasileira tem sob sua responsabilidade os mercados da América do Sul, América Central, México e África do Sul, entretanto, exporta para outras localidades além dessas. Nas Américas, seus principais mercados são Argentina, México, Chile e Venezuela, na África são Tunísia, Argélia, Egito, Marrocos e África do Sul, no Oriente Médio são Síria, Turquia e Irã e na Europa são Itália, Polônia, França e Espanha.

Quando a empresa transaciona com os mercados de sua área de atuação, a negociação é feita diretamente com o comprador, porém, quando a venda ocorre para os outros países, a 
matriz na Itália intermedia a transação. Dessa forma há três modalidades de vendas: a) para importadores dentro de sua área de atuação; b) para empresas do grupo dentro de sua responsabilidade; e c) para fora de seu âmbito de atividade. Nesse último caso, independente do cliente, o faturamento passa pela divisão italiana e, portanto, constitui-se em uma venda para empresa do grupo.

Na primeira modalidade, a determinação do preço dos produtos ocorre por meio de negociação direta com os importadores. Como estes são clientes finais, firma-se um contrato no qual se define o preço em Dólar por um determinado período. Na segunda modalidade, como as vendas são efetuadas para empresas do grupo, é utilizada uma das políticas de preço de transferência. Para a Argentina e África do Sul usa-se o PT com base no preço negociado fixado, também, em moeda norte-americana. Na última modalidade, a transação efetua-se diretamente com a matriz e, portanto, emprega-se um método específico de formação do preço. Para a Itália é utilizado o PT Administrado. A determinação é realizada de acordo com o custo do produto fabricado ao qual adiciona-se um mark-up e é fixada em Euro.

Nas transações com Preço Negociado as margens obtidas não sao satisfatórias para a empresa. Entretanto a mesma não pode aumentar o preço de acordo com seu interesse pois há um contrato a respeitar e tal aumento poderia deixar seus produtos mais caros que os concorrentes levando a uma perda de market share. Nas transações com Preço Administrado não há a possibilidade de alteração dos mesmos pois configura-se em uma regra imposta pela matriz com base no custo de produção que a filial brasileira é obrigada a seguir. Em ambos os casos, nas trasações intercompanies, uma eventual perda da empresa no Brasil reflete em ganho para a matriz ou outras filiais. Ao análisar as operações em uma ótica consolidada as perdas de uma unidade são compensadas pelos ganhos de outras.

Todas as operações de vendas a mercados internacionais estão atreladas ao Dólar ou Euro. Por outro lado, os custos dos produtos exportados são contratados em moeda brasileira. Dessa forma, a receita sofre influência das taxas de câmbio vigente e os custos não. Os dois métodos não variam conjuntamente e uma alteração na taxa de câmbio ou nos índices de inflação repercute somente em um dos fatores. Por consequëncia, os valores podem se distanciar, aproximar ou ser invertidos, ou seja, o custo tornar-se maior que o preço de venda.

\subsection{Impacto da variação cambial nos preços de exportação}

A valorização cambial ocorrida em 2005 causou impactos nos preços dos veículos exportados pela empresa nesse período. Além disso, os principais produtos destinados ao mercado externo são de baixo custo. Devido a esse fato, a maior parte do material empregado na fabricação provém de fornecedores brasileiros, não estando sujeita a variação cambial.

Nas vendas para países dentro de sua área de atuação (América Latina, México e África do Sul), seja para unidades do grupo ou para importadores diretos, a empresa negocia os preços em Dólar, os quais são contratados por certo período e, durante esse tempo, não podem ser ajustados. Dessa forma, utiliza-se o PT com base no preço negociado. Os custos, por sua vez, são pré-fixados em reais e variam conforme a inflação do Brasil. Nas exportações intermediadas pela matriz, o estabelecimento do PT segue a política do preço administrado. Portanto, usa-se uma regra arbitrada pela unidade matriz que será seguida pela filial. Para o Brasil, a norma toma como base o custo do produto fabricado.

Para determinar-se o preço, é utilizado o custo total de fabricação, somando-se ao preço o frete pago da fábrica até o porto de embarque e o seguro de transporte (all risk). Sobre essa base de cálculo aplica-se um percentual a título de margem de lucro. Apesar de ser utilizado um fator fixado em reais, no início de cada ano o PT é revisto e o valor em reais é convertido para Euros. Esse último consistirá no preço a ser praticado durante o ano corrente. Consequentemente, o preço de transferência passa a ser infuenciado pelas variações cambiais do ano em curso. 


\subsection{Análise do impacto da variação cambial no resultado do período}

No ano de 2005 a empresa apresentou a Demonstração dos Resultados do Exercício ilustrada no Quadro 1.

\begin{tabular}{|l|r|}
\hline DEMONSTRAÇÃO DO RESULTADO DO EXERCÍCO & valores em milhares de Reais \\
\hline RECEITA BRUTA DE VENDAS & 13.124 .266 \\
\hline Mercado Interno & 11.575 .006 \\
\hline Mercado Externo & 1.549 .260 \\
\hline IMPOSTOS S/ VENDAS E OUTRAS DEDUÇÕES & $(3.259 .518)$ \\
\hline RECEITA LÍQUIDA DE VENDAS & $\mathbf{9 . 8 6 4 . 7 4 8}$ \\
\hline CUSTO DOS PRODUTOS VENDIDOS & $(7.143 .105)$ \\
\hline LUCRO BRUTO & $\mathbf{2 . 7 2 1 . 6 4 3}$ \\
\hline RESULTADO OPERACIONAL & $(1.990 .537)$ \\
\hline LUCRO (PREJUÍZO) OPERACIONAL & $\mathbf{7 3 1 . 1 0 6}$ \\
\hline RESULTADO NÃO OPERACIONAL & 12.299 \\
\hline LUCRO (PREJUÍZO) LÍQUIDO ANTES DO IR E CS & $\mathbf{7 4 3 . 4 0 5}$ \\
\hline
\end{tabular}

Quadro 1 - Demonstração dos Resultados do Exercício de 2005

Fonte: adaptado das Demonstrações Contábeis publicadas do período de 2005.

As exportações, apesar de representarem $20 \%$ das vendas totais, correspondem, em termos monetários, a 11,8\% da receita bruta. Com isso as vendas internas trouxeram um retorno maior em relação às externas. A perda de rentabilidade na comercialização com o mercado internacional ocorreu em função da valorização do real frente ao Dólar e ao Euro.

Para analisar o impacto da variação cambial no resultado do período, ressalta-se inicialmente que a moeda norte americana apresentava equivalência de US\$1,00 $=\mathrm{R} \$ 2,6536$ no primeiro dia de 2005 e fechou o ano com US\$ $1,00=\mathrm{R} \$ 2,3399$, apresentando desvalorização de quase $12 \%$. A cotação chegou a ser US\$1,00 $=\mathrm{R} \$ 3,9544 \mathrm{em} \mathrm{2002}$. Ao comparar-se com esse índice de conversão a perda foi de 40,8\%. Em 31 de dezembro o Dólar voltou ao nível de abril de 2001. No mesmo período a moeda da comunidade Européia iniciou-se na paridade $€ 1,00=R \$ 3,6121$ e encerrou-se a $€ 1,00=R \$ 2,7669$, com depreciação de 23,4\%. Ao considerar-se a maior taxa, € 1,00 = R \$3,9719 em 2003, a perda de valor foi de 30,3\%. No fim do ano, o Euro voltou ao patamar de junho de 2002.

Ao longo dos anos de 2002 a 2004 as taxas de câmbio das duas moedas estrangeiras mantiveram-se em certo patamar e não variaram bruscamente. A média das paridades desse período constitui uma média histórica. Porém, no final de 2004, os índices de conversão começaram a cair e não pararam até o final do ano seguinte.

O Dólar de 2005 apresentou, desde o mês de janeiro, valores inferiores à média histórica. O Euro de 2005 foi, no início do ano, superior à média histórica, mas de maio em diante começou a perder valor. Essas reduções indicam o dano provocado no resultado da empresa que seria outro, caso o real não valorizasse frente às moedas estrangeiras. Se o nível cambial mantivesse o mesmo patamar, haveria um incremento nas receitas e, conseqüentemente, nos lucros.

Para encontrar a receita em reais, a empresa utiliza uma taxa denominada Câmbio Médio de Embarque, a qual consiste em uma média mensal ponderada pelas quantias recebidas nos dias de embarque de mercadorias. As transações efetuadas em moedas estrangeiras são convertidas à cotação do dia do embarque do produto no porto. Portanto, o câmbio do dia em que houver maior quantidade embarcada influenciará mais nos resultados das vendas mensais. $\mathrm{O}$ índice de conversão é obtido dividindo-se o valor total recebido em moeda brasileira pelo faturamento mensal em moeda estrangeira. $\mathrm{Na}$ Figura 1 expõem-se os 
valores da taxa ponderada encontrado pela empresa no ano de 2005, comparando-os com os da taxa histórica do período de 2002 a 2004.

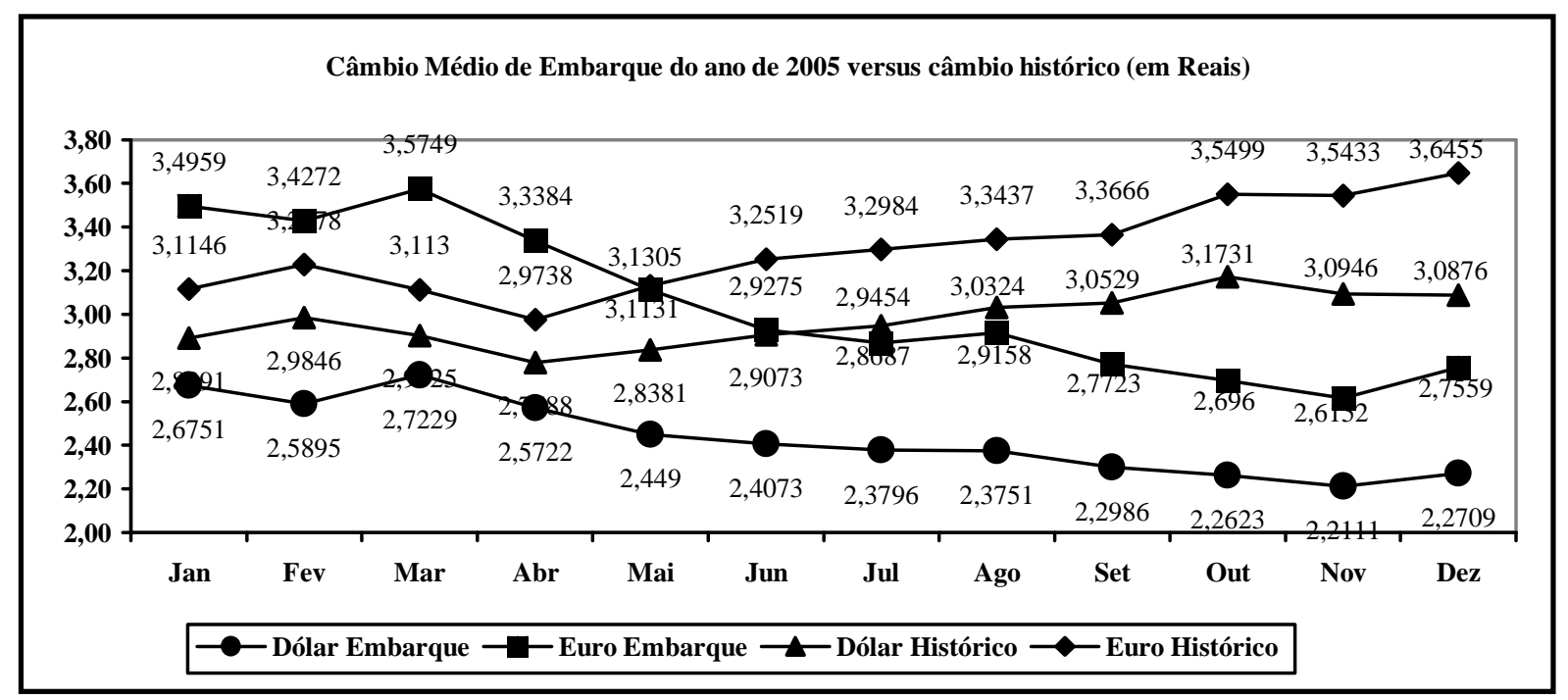

Figura 1- Câmbio médio de embarque do ano de 2005 versus câmbio histórico Fonte: adaptada dos registros da empresa.

Caso a paridade cambial da moeda brasileira com o Dólar e o Euro não sofresse variação brusca, como ocorrido no ano de 2005 , o resultado poderia ser diferente. No Quadro 2 compara-se os valores em reais das vendas faturadas em moeda estrangeira considerando-se as taxas de câmbio média de embarque e média histórica.

\begin{tabular}{|c|c|c|c|c|}
\hline \multirow{2}{*}{ Mês } & \multicolumn{2}{|c|}{ Faturamento na Moeda de Origem } & \multicolumn{2}{|c|}{$\begin{array}{c}\text { Total equivalente em milhares de R\$ } \\
\text { Câmbio Médio Histórico }\end{array}$} \\
\hline & $\begin{array}{c}\text { Faturado em } \\
\text { milhares de US\$ }\end{array}$ & $\begin{array}{l}\text { Faturado em } \\
\text { milhares de } €\end{array}$ & $\begin{array}{l}\text { Câmbio Médio de } \\
\text { Embarque }\end{array}$ & $\begin{array}{c}\text { Câmbio Médio } \\
\text { Histórico }\end{array}$ \\
\hline Janeiro & 24.124 & 4.515 & 80.318 & 83.759 \\
\hline Fevereiro & 19.223 & 8.230 & 77.984 & 83.938 \\
\hline Março & 34.701 & 16.285 & 152.705 & 151.415 \\
\hline Abril & 40.112 & 15.171 & 153.823 & 156.579 \\
\hline Maio & 40.603 & 18.242 & 156.226 & 172.343 \\
\hline Junho & 47.081 & 17.073 & 163.319 & 192.397 \\
\hline Julho & 46.538 & 17.183 & 160.035 & 193.750 \\
\hline Agosto & 34.992 & 13.328 & 121.971 & 150.673 \\
\hline Setembro & 41.314 & 8.264 & 117.875 & 153.948 \\
\hline Outubro & 33.827 & 15.864 & 119.296 & 163.650 \\
\hline Novembro & 38.028 & 18.266 & 131.853 & 182.401 \\
\hline Dezembro & 40.939 & 7.579 & 113.855 & 154.031 \\
\hline Total & 441.482 & 160.000 & 1.549 .260 & 1.838 .884 \\
\hline
\end{tabular}

Quadro 2 - Reconstrução da receita bruta de vendas ao mercado externo do ano de 2005 utilizando-se taxas média de embarque e média histórica de 2002 a 2004

Fonte: elaborado pelos autores.

Observa-se que a receita de exportação da empresa seria maior caso as moedas estrangeiras não desvalorizassem fortemente frente à nacional e mantivessem-se os níveis registrados nos três anos anteriores ao analisado. $\mathrm{O}$ valor encontrado seria em torno de 300 milhões superior ao valor divulgado. A diferença representa cerca de $19 \%$ do faturamento das vendas externas. Da mesma forma que ocorrido na receita, o resultado da companhia seria 
diferente. $\mathrm{O}$ aumento nos valores recebidos em Reais melhoraria o lucro do exercício. No Quadro 3 expõe-se a Demonstração dos Resultados do Exercício com a receita de exportação convertida à taxa média histórica

\begin{tabular}{|l|r|}
\hline DEMONSTRAÇÃO DO RESULTADO DO EXERCÍCO & valores em milhares de Reais \\
\hline RECEITA BRUTA DE VENDAS & 13.124 .266 \\
\hline Mercado Interno & 11.575 .006 \\
\hline Mercado Externo & 1.838 .884 \\
\hline IMPOSTOS S/ VENDAS E OUTRAS DEDUÇÕES & $3.259 .518)$ \\
\hline RECEITA LÍQUIDA DE VENDAS & $\mathbf{1 0 . 1 5 4 . 3 7 2}$ \\
\hline CUSTO DOS PRODUTOS VENDIDOS & $(7.143 .105)$ \\
\hline LUCRO BRUTO & $\mathbf{3 . 0 1 1 . 2 6 7}$ \\
\hline RESULTADO OPERACIONAL & $(1.990 .537)$ \\
\hline LUCRO (PREJUÍZO) OPERACIONAL & $\mathbf{1 . 0 2 0 . 7 3 0}$ \\
\hline RESULTADO NÃO OPERACIONAL & 12.299 \\
\hline LUCRO (PREJUÍZO) LÍQUIDO ANTES DO IR E CS & $\mathbf{1 . 0 3 3 . 0 2 9}$ \\
\hline
\end{tabular}

Quadro 3 - Demonstração dos Resultados do Exercício de 2005 com receita de exportação convertida à taxa média histórica

Fonte: elaborado pelos autores.

Ao se comparar as Demonstrações de Resultado do Período, observa-se que o incremento de 289,6 milhões na receita de exportação reflete diretamente no lucro antes do Imposto de Renda, uma vez que os custos são provenientes de negociações em reais e não se alteram em função da valorização do real. A variação no lucro representa um aumento de $39 \%$ em relação ao resultado registrado pela empresa no ano de 2005. Na Figura 2 apresentam-se as variações da Receita Bruta de Exportação e do Lucro antes do Imposto de Renda.

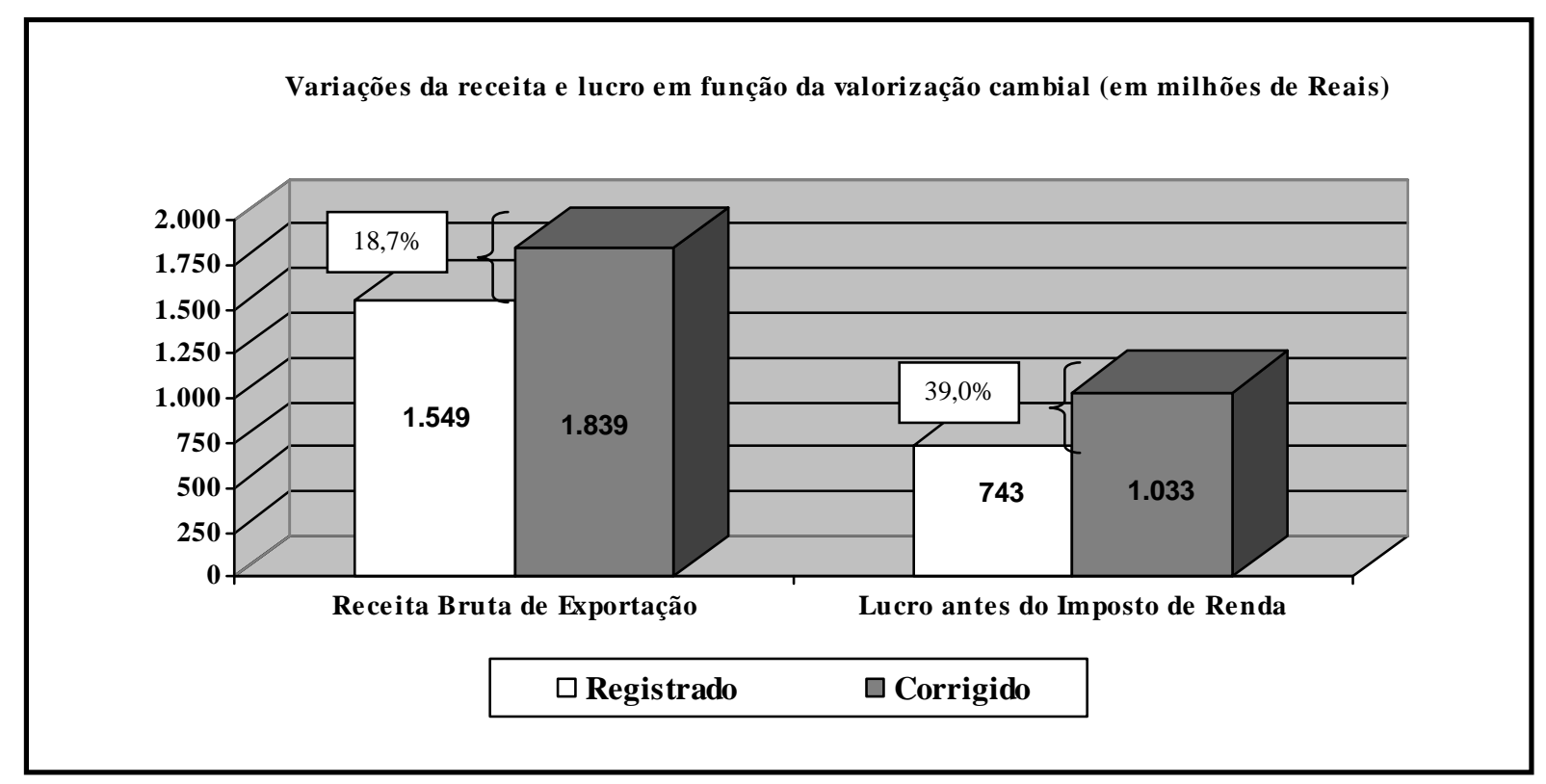

Figura 2 - Variações da receita e lucro em função da valorização cambial Fonte: elaborada pelos autores.

Por fim, a desvalorização das moedas estrangeiras frente à nacional impactou negativamente nas operações da companhia. $O$ faturamento das vendas externas ao ser convertido à unidade monetária brasileira passou a equivaler a valores inferiores aos registrados nos anos anteriores. Caso a paridade cambial se mantivesse no mesmo patamar dos anos de 2002 a 2004 a empresa obteria uma receita 18,7\% superior à registrada no 
período analisado e um lucro 39\% maior. Além disso, em função dos prejuízos trazidos por tal fenômeno o volume de vendas foi reduzido e foram comercializados somente 90 mil veículos, em detrimento aos 120 mil pretendidos, ou seja, uma produção de $75 \%$ do previsto.

\section{CONCLUSÕES}

O Preço de Transferência é utilizado pelas companhias para transferir produtos de uma unidade divisional para outra, possibilitando a avaliação do desempenho das mesmas. No ambiente internacional, é empregado na venda para outra unidade do mesmo grupo situada em outro país, visando à minimização do impacto da tributação sobre a operação. Nas transações com o mercado externo o PT sofre influência das variações cambiais.

Quanto aos objetivos da pesquisa, o trabalho apresentou o processo de formação do PT na Fiat Automóveis S/A. Observou-se que companhia emprega o Preço Negociado quando transaciona com países sob sua responsabilidade comercial e o Preço Administrado ao comercializar com os demais mercados, utilizando a matriz como intermediadora do processo. Reconheceu-se a variação cambial da moeda nacional em comparação às estrangeiras que se valorizou cerca de $15 \%$ em relação ao Dólar e $23 \%$ ao Euro e formou-se uma média histórica da taxa de câmbio. Evidenciou-se o resultado contábil do período ao corrigi-lo pela média histórica, encontrando uma receita de exportação de $\mathrm{R} \$ 1.84$ bilhões e lucro de $\mathrm{R} \$ 1,03$ bilhão. Identificou-se ainda o impacto no resultado do período decorrente da variação cambial. Conclui-se que a Receita Bruta de Vendas seria 300 milhões superior à registrada caso a valorização do Real não ocorresse, representando uma diferença de 19\%. O Lucro antes do Imposto de Renda seria 39\% maior que o obtido no ano analisado, caso esse fenômeno não se confirmasse. Assim, acredita-se que o estudo propiciou a verificação do impacto da valorização do Real comparado ao Dólar e Euro no resultado do período da empresa que utilizou o Preço de Transferência para mensuração das receitas de exportação.

Como sugestão para novas pesquisas, acredita-se que outros fatores podem maximizar ou minimizar o efeito da alteração das taxas de câmbio nos resultado das companhias. Assim, sugere-se como continuidade do estudo avaliar a influência da tributação no resultado encontrado utilizando-se a média histórica da taxa de câmbio. Considerar, portanto, a influência do Imposto de Renda e da Contribuição Social para identificar o impacto sobre o resultado do período. E ainda, analisar o efeito da Lei de Transfer Prince para redução da receita em função da valorização do real. Verificar o aspecto do Preço de Referência para tributação do Imposto de Renda abordado pela legislação e a taxação extra em função do não atendimento das disposições legais.

\section{REFERÊNCIAS}

ALMEIDA, Marcelo Cavalcanti. Contabilidade avançada: de acordo com as novas exigências do MEC para o curso de Ciências Contábeis: textos, exemplos e exercícios resolvidos. São Paulo: Atlas, 1997.

ANTHONY, Robert N.; GOVINDARAJAN, Vijay. Sistemas de controle gerencial. São Paulo: Atlas, 2000.

ATKINSON, Anthony A. et al. Contabilidade gerencial. São Paulo: Atlas, 2000.

GAROFALO FILHO, Emilio. Câmbios no Brasil: as peripécias da moeda nacional e da política cambial, 500 anos depois. São Paulo: Cultura Editores Associados, 2000.

GARRISON, Ray H.; NORREN, Eric W. Contabilidade gerencial. 9. ed. Rio de Janeiro: LCT, 2001.

GIL, Antônio Carlos. Métodos e técnicas de pesquisa social. 5. ed. São Paulo: Atlas, 1995. 
HANSEN, Don R.; MOWEN, Maryanne M. Gestão de custos. São Paulo: Pioneira Thomson Learning, 2003.

HENDRIKSEN, Eldon S.; VAN BREDA, Michael F. Teoria da contabilidade. 5. ed. São Paulo: Atlas, 1999.

HILTON, Ronald W. Managerial accounting. 3 ed. Boston: McGraw Hill, 1997.

MEDEIROS, Rodrigo. Preço de transferência: uma ferramenta para a eficácia das organizações. (Monografia) - Pós-graduação em Finanças e Contabilidade, Universidade de Taubaté, 2000.

MOFFITT, Michael. $O$ dinheiro do mundo: de Bretton Woods à beira da insolvência. Rio de Janeiro: Paz e Terra, 1984.

PEREIRA, Thiago Rabelo; CARVALHO, Alexandre. Desvalorização cambial e seu impacto sobre os custos e preços industriais no Brasil: uma análise dos efeitos de encadeamento nos setores produtivos. Boletim Política Industrial DISET IPEA. Brasília, mar. 2000.

PEREIRA, Carlos Alberto; OLIVEIRA, Antonio Benedito Silva. Preço de transferência: uma aplicação do conceito do custo de oportunidade. In: Catelli, Armando (coord). Controladoria: uma abordagem da gestão econômica. São Paulo: Atlas, 2001.

REZENDE, Fernanda Carneiro de. O impacto da desvalorização cambial nas commodities. (Monografia) - Pontifícia Universidade Católica do Rio de Janeiro, 1999.

RICHARDSON, Roberto Jarry. Pesquisa social: métodos e técnicas. São Paulo: Atlas, 1999.

SIMONSEN, Mário Henrique. 30 anos de indexação. Rio de Janeiro: Editora da Fundação Getúlio Vargas, 1995.

WACHHOLZ, Carla; BENETTI, Cristiane; REGINATO, Luciane. O Preço de transferência interdivisional baseado no custo de oportunidade: uma contribuição à gestão de custos. In: CONGRESSO INTERNACIONAL DE CUSTOS, 9., 2005, Florianópolis. Anais... São Leopoldo: ABC, 2005. CD-ROM.

WARREN, Carl S.; REEVE, James M.; FESS, Philip E. Contabilidade gerencial. São Paulo: Pioneira Thomson Learning, 2001.

YIN, Robert K. Case study research: design and methods. Beverly Hills: Sage Publications, 1984. 